\title{
History of Respiratory Stimulants
}

This article was published in the following Dove Press journal:

Journal of Pain Research

\author{
John F Peppin ${ }^{1,2}$ \\ Joseph V Pergolizzi Jr $\mathbb{D}^{3-5}$ \\ Jeffrey Fudin ${ }^{6-8}$ \\ Tricia A Meyer 9 \\ Robert B Raffa $3,5,10,11$ \\ 'Marian University College of \\ Osteopathic Medicine, Indianapolis, IN, \\ USA; ${ }^{2}$ Pikeville University College of \\ Osteopathic Medicine, Pikeville, KY, USA; \\ ${ }^{3}$ Enalare Therapeutics Inc., Princeton, NJ, \\ USA; ${ }^{4}$ NEMA Research Inc., Naples, FL, \\ USA; ${ }^{5}$ Neumentum Inc., Summit, NJ, \\ USA; ${ }^{6}$ Western New England College of \\ Pharmacy, Springfield, MA, USA; ${ }^{7}$ Albany \\ College of Pharmacy \& Health Sciences \\ Union University, Albany, NY, USA; \\ ${ }^{8}$ Remitigate Therapeutics, Delmar, NY, \\ USA; ' Texas A\&M College of Medicine, \\ Bryan, TX, USA; ${ }^{10}$ University of Arizona \\ College of Pharmacy, Tucson, AZ, USA; \\ "Temple University School of Pharmacy, \\ Philadelphia, PA, USA
}

Correspondence: Robert B Raffa $\mathrm{Tel}+\mid$ 610-29|-7019

Email robert.raffa@temple.edu

\begin{abstract}
The interest in substances that stimulate respiration has waxed and waned throughout the years, intensifying following the introduction of a new class of drugs that causes respiratory depression, and diminishing when antidotes or better drug alternatives are found. Examples include the opioids - deaths increasing during overprescribing, diminishing with wider availability of the opioid receptor antagonist naloxone, increasing again during COVID-19; the barbiturates - until largely supplanted by the benzodiazepines; propofol; and other central nervous system depressants. Unfortunately, two new troubling phenomena force a reconsideration of the status-quo: (1) overdoses due to highly potent opioids such as fentanyl, and even more-potent licit and illicit fentanyl analogs, and (2) overdose due to polysubstance use (the combination of an opioid plus one or more non-opioid drug, such as a benzodiazepine, sedating antidepressant, skeletal muscle relaxant, or various other agents). Since these now represent the majority of cases, new solutions are again needed. An interest in respiratory stimulants has been revived. This interest can be informed by a short review of the history of this interesting class of medications. We present a short history of the trajectory of advances toward more selective and safer respiratory stimulants.
\end{abstract}

Keywords: overdose, respiratory depression, respiratory stimulant, carotid body, potassium channels

\section{Introduction}

As the pattern of substance abuse and overdose death has changed over the last few decades, there has evolved the attendant realization that the current approach to overdose needs to be updated. ${ }^{1}$ The current standard drug used in presumptive opioid-related overdoses, the opioid receptor antagonist naloxone, has a receptor binding affinity that is increasingly less competitive against the ever more-potent fentanoids (such as alfentanil, carfentanil, fentanyl, and sufentanil), and illicit "fentalogues", 2 and is a mechanistic mismatch for respiratory depression induced by the non-opioid component in polysubstance overdoses, which unfortunately are currently the rule, not the exception. ${ }^{3,4}$ This does not mean that the use of naloxone should be abandoned, quit the contrary. However, supplementation to its use needs to be considered. With the added complication of designer fentalogues entering the illicit market, overdose deaths have continued to rise in spite of efforts at curtailment. There is thus a growing interest in developing non-opioid-based therapies that can help improve outcomes in these cases, that is, be an "agnostic" respiratory ventilator (one that improves respiratory function independent of the chemical cause)..$^{5}$ This has led to a revitalized interest in compounds that are respiratory stimulants. 
Concern over drug-induced respiratory depression goes back centuries. It was highlighted in the 1850 s after the first recorded death by morphine-induced respiratory depression. ${ }^{6,7}$ And the same concern was expressed again with recognition of the problem of difficulty in trying to reverse barbiturate-induced respiratory depression. And recently there has been another revival in interest due to the common use of propofol, benzodiazepines, and other drugs that either alone or in (additive or synergistic) combination produce potentially fatal respiratory depression. Each time, an interest in stimulation of respiration has been rekindled. This paper presents a short overview of the history of respiratory stimulants.

\section{Analeptics}

The early substances used to stimulate respiration were generalized non-selective central nervous system (CNS) stimulants. The term "analeptic" was applied to describe the stimulating actions of these agents, which worked by diverse physiologic mechanisms. Analeptics were used for a multitude of clinical purposes for over 200 years. However, they were mostly used in four general areas: CNS/respiratory-depression or coma; severe CNS/respiratory depression from drug overdose; poisoning and moderate $\mathrm{CNS} /$ respiratory-depression from anesthetics; and moderate respiratory depression resulting from therapeutic doses of peri- and post-operative drugs, such as anesthetics. ${ }^{8,9}$ Advancements in basic pharmacologic science and clinical experience have discovered that all analeptics do cause respiratory stimulation (often indirectly), but not all respiratory stimulants are truly analeptic. The diversity of action of analeptics can be appreciated by three broad categories: psychomotor stimulants, psychotomimetics (hallucinogens), and respiratory stimulants. They invoked cortical, brainstem, and spinal cord excitation, which was found to be useful for a wide range of clinical applications in the fields of anesthesia, pain medicine, intensive care, and psychiatry, as well as respiratory medicine. ${ }^{10}$ Since the use of non-specific CNS stimulants in clinical practice has now waned, the remaining selective agents are used mainly for respiratory stimulation, so the term "analeptic" has basically come to be synonymous in modern usage with "respiratory stimulant". ${ }^{10}$

The group of drugs that can stimulate respiration have a variety of different mechanistic actions that involve both direct and indirect effects at both central and peripheral targets: $:^{10}$
- Direct receptor activation, e.g., ephedrine (a noncatecholamine adrenoceptor agonist).

- Competitive antagonism of inhibitory receptors, e.g., atropine (a competitive muscarinic acetylcholine receptor antagonist).

- Promotion of neurotransmitter release from presynaptic nerve terminals, e.g., ephedrine, amphetamines (which specifically increase release of monoamine neurotransmitters).

- Inhibition of neuronal neurotransmitter reuptake, e.g., cocaine, methylphenidate (which increase synaptic concentration of neurotransmitters).

- Inhibition of second messenger degradation, e.g., methylxanthines (which magnify or prolong the action of neurotransmitters).

\section{Respiratory Stimulants}

Perhaps the earliest published reference to medicinal respiratory stimulation was in $1774 .{ }^{11}$ It was recommended that introducing tobacco smoke into a patient's lungs would resuscitate a patient who had drowned. ${ }^{11}$ Nicotine in tobacco smoke is an agonist at nicotinic acetylcholine receptors located peripherally at neuromuscular junctions and centrally.

Awareness of strychnine's toxic and medicinal effects dates back to ancient times. Strychnine, in the form of seeds from the Strychnos nux-vomica tree, was used as a rodenticide in the 16 th century. ${ }^{12}$ It is a white odorless, bitter tasting alkaloid, and was an ingredient in "Easton's Syrup", used for a variety of disorders. ${ }^{13}$ Easton's Syrup was still available in the 1960s and could be obtained from local pharmacists in various dosage forms and combinations, ${ }^{14}$ during which case reports of overdoses were published. ${ }^{13}$ As with almost all physiologic processes in the human body, there is a balance between stimulation and inhibition. So too with the CNS, and the interactions between excitatory and inhibitory nervous inputs. The principle stimulatory neurotransmitter is glutamate (along with aspartate), and GABA and glycine are the principle inhibitory molecules. ${ }^{15}$ Strychnine antagonizes glycine binding to its receptor (NMDA, $N$-Methyl-D-aspartate) with high affinity. ${ }^{15,16}$ It also is an antagonist of acetylcholine receptors. ${ }^{15}$ Since glycine is inhibitory in the CNS, stimulatory processes become dis-inhibited. Seizure, muscle contractions, and death can result from an overdose. Although known for centuries, strychnine use was "discovered" in $1818 .{ }^{17}$ It was used medicinally as one of the first analeptics for the purpose of stimulating respiration. 
In 1939, anesthesiologists were employing respiratory analeptics such as strychnine routinely, "we have become more willing to employ analeptics early during the period of anesthesia". 18

Ephedrine is found in the Chinese herb Ma Huang, which has been used for over 5000 years. ${ }^{19}$ In 1885 ephedrine was identified as the active ingredient, which was further clarified in 1887 in Japan. ${ }^{19}$ Ephedrine is a stereoisomer of pseudoephedrine and a sympathomimetic amine. It acts as both a direct and indirect sympathomimetic, as it binds directly to adrenoceptors, ${ }^{20}$ and also inhibits neuronal norepinephrine reuptake, its primary mechanism of action. ${ }^{21}$ Ephedrine has been used since the 1920s as a bronchodilator, nasal decongestant, and in the treatment of urinary incontinence. As a respiratory stimulant, the reports are mixed. In 1926 ephedrine was reported to have no significant effect on human respiratory rate or depth. ${ }^{22}$ But in 1929 Schmidt reported that ephedrine was more effective than the other respiratory stimulants used at the time. ${ }^{22}$ In 1939 it was reported that ephedrine was given during surgery and post-operatively, and postoperatively strychnine was given "every three hours for three doses". 18

Atropine was being used as a respiratory stimulant in the early 1900s and is still used today in the setting of organophosphate poisoning and to control secretions during surgery. ${ }^{23,24}$ Atropine is an antagonist of muscarinic acetylcholine receptors, which leads to parasympathetic inhibition and dominance of sympathetic stimulation. ${ }^{24}$ However, a study in the 1950s applying atropine to morphine-induced respiratory depression stated that atropine, "contrary to common teachings, is not a respiratory stimulant". 25

Amphetamines as a class of drugs were introduced into the United States in the 1930s as respiratory stimulants for asthma and nasal congestion. Similar to cocaine, amphetamines block catecholamine reuptake and have moderate effect on blocking serotonin and dopamine reuptake. However, unlike cocaine, amphetamines have no significant effect on sodium or potassium ion channels. ${ }^{26}$ In 1945 , amphetamine was said to be "the most effective drug" to reverse morphine-induced respiratory depression. ${ }^{23}$ However, due to its side effects and its own abuse potential, amphetamines fell out of favor as a post-operative respiratory stimulant.

Cocaine is extracted as a paste from the leaves of a plant from the Erythroxylum coca species such as found in the Andean and Amazon areas of South America. During the 19th and early 20th centuries cocaine was used for a variety of respiratory disorders. ${ }^{27}$ It was used as a respiratory stimulant, but problems of substance use disorder became a serious public health problem, and cocaine use post-surgically was found to be ineffective. ${ }^{26}$ The pharmacologic mechanism of action of cocaine is complex. Cocaine blocks neuronal catecholamine and serotonin reuptake and stimulates catecholamine release. It blocks sodium and potassium channels, and has some effect on calcium channels. ${ }^{26}$

Carbon dioxide was used as a respiratory stimulant in the 1930s, along with other agents. It was described as the "outstanding member of this group" of respiratory stimulants, of those tested. ${ }^{23}$ Interestingly, the first use of carbon dioxide was for controlling respirations during anesthesia. $^{28}$ But this treatment fell out of favor, as the worrisome secondary effects of carbon dioxide inhalation became better recognized.

Picrotoxin, derived from the Fishberry shrub, has been used for centuries to stun fish. ${ }^{29}$ It is a noncompetitive antagonist at the $\gamma$-aminobutyric-A (GABA-A) receptor complex, and has been used as a neuro-stimulant and proconvulsant. It was used to stimulate respiration in the setting of barbiturate toxicity. ${ }^{29}$ In the 1940 s the US military studied some stimulatory agents, including picrotoxin, in an effort to improve stamina and work output. ${ }^{30}$ In a 1948 study, picrotoxin was found to be more effective than amphetamine and nikethamide (Coramine) for respiratory stimulation. ${ }^{31}$ Picrotoxin blocks glycine channels, which can create a similar physiological condition to strychnine poisoning. ${ }^{15}$ However, due to its toxicity and narrow therapeutic window, picrotoxin fell out of medical use.

Tetrazole derivatives (synthetic organic heterocyclic compounds consisting of a five-member ring of four nitrogen atoms and one carbon atom) act on the CNS. The most prominent, Leptazol (pentamethylenetetrazole), was originally synthesized in 1924. It increases cAMP and increases release of acetylcholine, but produces its simulant effects mainly through GABA. ${ }^{32}$ In the 1940 s it was suggested that Leptazol should be used in place of picrotoxin and nikethamide (Coramine), since it is less toxic. ${ }^{33}$ Again, research did not support the use of Leptazol as a safe and significant respiratory stimulant.

In the 1950s there was growing concern about the use of the available analeptics, with clinicians divided on the subject of the use of analeptics for barbiturate toxicity and respiratory depression. ${ }^{34}$ At the time, picrotoxin, Leptazol, 
Geastimol, amphetamine, and nikethamide (Coramine) were the respiratory analeptics available.

In the 1960s, methylphenidate was introduced and was used as a respiratory stimulant for a short period. ${ }^{31}$ By the end of the 1960s, all analeptics had fallen out of favor. A controlled study of nikethamide (Coramine), dimefline and prethcamide done in 1969 made the following statement,

Despite claims to the contrary, the results of this critical and controlled study of the effects of different respiratory stimulants in chronic respiratory failure did not document changes in action or efficacy. ${ }^{35}$

The study showed only "minimal" improvements and a very short duration of action with these drugs, further supporting the discontinuation of this class of medications. Sanchez-Salazar wrote in 1963 "the use of analeptics in the management of respiratory depression has been limited" for three reasons: the failure of respiratory stimulation in some cases, increased metabolism with resultant decreased oxygen available, and the short-lived stimulation. ${ }^{36}$ In the early 1960 s an editorial on respiratory stimulants stated, "anesthesiologists have little need for respiratory stimulants". ${ }^{37}$ And another of the same time stated, "analeptics are not a substitute for and are a dangerous supplement to good postoperative medical and nursing care."

But it was not long before almitrine was developed (the 1970s). Almitrine (6-[4-[Bis(4-fluorophenyl)methyl]piperazin-1-yl]- $N, N$-diprop-2-enyl-1,3,5-triazine-2,4-diamine) increases tidal volume and respiratory rate. ${ }^{38}$ It was considered a new-generation of respiratory analeptic, and it was used due to its clinical effects of improvement of minute ventilation and decreased $\mathrm{PCO}_{2}$ due to stimulation of chemoreflexes, and vasoconstriction of pulmonary vessels in hypoxic zones, which improves oxygen tension in arterial blood. ${ }^{39}$ More specifically, almitrine stimulates TASK-1 and TASK-3 potassium channels in the carotid body. Never approved in the United States, its sale was subsequently banned in the European Union and the United Kingdom. It is considered unsuitable for clinical practice because of a significant incidence of peripheral neuropathy caused by its metabolites. ${ }^{40}$

Caffeine deserves special mention. It was found to have very little effect in overcoming respiratory depression. However, it is still in use today in neonatology practice. Caffeine, a methylxanthine, although a weak bronchodilator, is used in three clinical settings: asthma (rarely), apnea of prematurity, and newborn bronchopulmonary dysplasia. ${ }^{41}$ From a statement published in 1990: "So far, however, respiratory stimulants have provided little convincing therapeutic benefit and many undesirable side effects." 42

Of all the medications and substances used to stimulate respiration over the last 200 years, doxapram (1-Ethyl-4(2-morpholin-4-ylethyl)- 3,3-diphenyl-pyrrolidin-2-one; Dopram) remained into the 21 st century. With the development of doxapram in 1962, interest in respiratory stimulants was renewed. Doxapram increases respiratory rate and tidal volume as well as a perceived higher safety profile than previous drugs. ${ }^{43}$ Doxapram acts by stimulating chemoreceptors in the aortic and carotid bodies, thereby stimulating respiratory centers with resultant increased rate and depth of respiration. ${ }^{44}$ The term "pharmacologic ventilator" was used to describe doxapram in 1966, a term that was further applied to other respiratory analeptics. ${ }^{5}$ A double-blinded study of doxapram hydrochloride, nikethamide (Coramine), prethcamide, amiphenazole, and ethamivan performed in 1967 indicated that doxapram was superior in stimulating respiration over the other drugs tested. ${ }^{45}$ A 2004 Cochrane review of doxapram use in preterm infants, found that the drug reduces apnea of prematurity. ${ }^{46}$ Doxapram is still available today, and used, as a respiratory analeptic. Common adverse effects are restlessness, muscle twitching, and vomiting, and seizures can occur due to stimulation of the central nervous system.

The recent review by Iman et al provides a comprehensive Table of molecules/targets assessed for ability to counter respiratory depression (induced by opioids, but applicable to other inducers).$^{47}$ Of the many listed and not already discussed in detail, such as ampakine, 5-HT (1A, 4A, 4, and or 7) agonist, PDE-4 inhibitor, D1 dopamine receptor agonist, BK-channel blocker, nicotine acetylcholine receptor agonist, NMDA receptor antagonist, PKA inhibitor, GIRK channel blocker, alpha $2^{-}$ adrenoceptor antagonist, $\mathrm{AChE}$ inhibitor, and a few others, only the ampakine CX717, almitrine (discussed above), doxapram (discussed above), and GAL021 (now ENA021) have been tested in humans to our knowledge. Another target tested in animal models is the cannabinoid CB2 receptor. The selective $\mathrm{CB} 2$ receptor agonist AM2301 significantly attenuated morphine-induced respiratory depression in male mice. ${ }^{48}$ To our knowledge, a CB2 agonist has not been tested for this purpose in humans. 
Ampakines (also AMPAKINE $^{\circledR} \mathrm{s}$, AMPAkines) are a chemical, and more broadly a pharmacologic, class of agents that act as positive allosteric modulators of the AMPA $(\alpha-$ Amino-3-hydroxy-5-Methyl-4-isoxazole Propionic Acid) subtype of glutamate receptor. AMPA receptors mediate the effects of glutamate and participate in the maintenance of respiratory rhythmogenesis within the pre-Bötzinger complex in the brainstem. ${ }^{49-51}$ In a proof-of-concept study in healthy male volunteers, pretreatment with the ampakine CX717, ${ }^{52,53}$ significantly mitigated the decrease in ventilatory frequency induced by alfentanil $(2.9 \pm 33.4 \%$ with CX717 compared to $25.6 \pm 27.9 \%$ with placebo). CX717 did not significantly reverse measures of alfentanil analgesia. It was tolerated by all subjects, with no side effects requiring interventions (but it did result in significantly more pronounced increase in tiredness). Clinical utility in emergency situations might be limited by: the slow onset of action of the oral formulation $\left(\mathrm{C}_{\max } \approx 2 \mathrm{~h}\right)$ and lack of published clinical efficacy against respiratory depression induced by agents other than opioids (although the existence of AMPA receptor sites outside the preBötzinger complex, albeit still in the CNS, might allow this). A search of ClinicalTrials.gov for ampakine and respiratory depression yielded no results.

Another compound tested in humans is esketamine, which is the $S(+)$ enantiomer of ketamine. Esketamine is a non-competitive NMDA receptor antagonist and is a dopamine reuptake inhibitor, but it does not bind significantly to $\sigma$ receptors. In a randomized, double-blind, placebo-controlled, crossover-design study in healthy young male and female volunteers, esketamine effectively countered remifentanil-induced respiratory depression. ${ }^{54}$ The most common adverse effect was nausea. The authors speculate about possible mechanisms of action, including: a sympathomimetic action, since esketamine increases sympathetic outflow and inhibits the reuptake of norepinephrine; antagonism of NMDA receptors; and an action of the esketamine metabolite hydroxynorketamine on AMPA receptors, in a manner possibly similar to that of the ampakines.

The most recent respiratory stimulant entrant is ENA001, which is currently in development. It has received attention as an "agnostic" respiratory stimulant for a number of disease states, as well as for opioid-induced respiratory depression. It inhibits large-conductance $\mathrm{Ca}^{2}$ ${ }^{+} /$voltage-activated "big" $\mathrm{K}^{+}$channels, $\mathrm{BK}_{\mathrm{Ca}} \cdot{ }^{55}$ It has been shown to increase minute ventilation in a dose-dependent manner, and to reverse opioid, benzodiazepine, isoflurane and propofol-induced respiratory depression. ${ }^{56}$ The original research that established ENA-001 as a respiratory stimulant without reversing analgesia came from animal studies. ${ }^{40}$ It has now been shown to antagonize opioid-induced respiratory depression in healthy volunteers. ${ }^{57}$ Since it has been shown to stimulate respiration in both benzodiazepine and opioid excess, it offers a potential agent for the care of "polysubstance" patients. A further benefit of ENA-001 is "rapid onset time/offset time" which has been claimed to make "this drug an attractive alternative to naloxone". 58

\section{Caveats}

From a practical standpoint, some of the centrally-acting analeptics discussed carry an elevated seizure-risk. When reversing a mixed benzodiazepine/opioid overdose with flumazenil/naloxone, centrally-acting analeptics could be a problematic or dangerous option because of a heightened seizure-risk from benzodiazepine withdrawal. ${ }^{59,60}$

At this time in the history of so many overdose deaths, naloxone still reserves a critically important place in treating opioid overdose, and should be administered as early in the episode as possible. The use of a peripheral "agnostic" respiratory stimulant, alone or in combination with naloxone, might be a valuable addition to the currently available options, vide infra.

\section{Conclusion}

Throughout history, substances have been sought that would reverse disease-, poison-, or therapeutic druginduced respiratory depression. In contradistinction to receptor blockade by an antagonist, which in modern times is hampered by ever-more-potent agonists and polysubstance-induced respiratory depression, various approaches to achieve direct stimulation of respiration have been tried. Such an approach would be "agnostic" to the cause, and therefore universally effective. Multiple medications have been tried-with limited success due to lack of sufficient efficacy or safety concerns - as described herein. The newest drugs target specific subtypes of potassium channels located on tissue located outside the CNS (carotid body), accounting for their significantly reduced CNS adverse effects. Only time will tell if the long-sought search for a respiratory analeptic is near realization, or if the new drugs, like the previous ones, will enter into the "history" of respiratory stimulants that have been found wanting. 


\section{Disclosure}

JVP and RBR are co-founders of Enalare Therapeutics Inc., which owns and is developing ENA-001. JVP is an employee of NEMA Research Inc., and discloses the following relationships: he is consultant and/or speaker and researcher for Spirify, US World Meds, Salix, Enalare, Scilex, Pfizer, Lilly, Teva, Takeda, Regeneron, Grünenthal, Neumentum, BDSI, and Bridge Therapeutics. He owns stock in Neumentum, NEMA Research, Enalare Therapeutics, and Bridge Therapeutics. RBR is a consultant for Neumentum, BDSI, and Bridge Therapeutics. He owns interest in Enalare Therapeutics and stock options in Neumentum and Bridge Therapeutics. JFP is a medical monitor and consultant for Relmada. JF is a consultant and/or speaker for Abbott, AcelRx, BDSI, Firstox, GSK, Hisamitsu, Hikma, Scilex, and Salix. TAM is a consultant for AcelRX and speaker for Acacia. The authors report no other potential conflicts of interest for this work.

\section{References}

1. Peppin J, Raffa R, Schatman M. The polysubstance overdose-death crisis. J Pain Res. 2020;13:3405-3408. doi:10.2147/JPR.S295715

2. Persico AL, Wegrzyn EL, Fudin J, Schatman ME. Fentalogues. $J$ Pain Res. 2020;13:2131-2133. doi:10.2147/JPR.S265901

3. Connor JP, Gullo MJ, Chan G, Young RM, Hall WD, Feeney GF. Polysubstance use in cannabis users referred for treatment: drug use profiles, psychiatric comorbidity and cannabis-related beliefs. Front Psychiatry. 2013;4:79. doi:10.3389/fpsyt.2013.00079

4. Connor JP, Gullo MJ, White A, Kelly AB. Polysubstance use: diagnostic challenges, patterns of use and health. Curr Opin Psychiatry. 2014;27(4):269-275. doi:10.1097/YCO.0000000000000069

5. Winnie AP, Collins VJ. The search for a pharmacologic ventilator. Acta Anaesthesiol Scand Suppl. 1966;23:63-71. doi:10.1111/j.13996576.1966.tb00993.x

6. Seturner F. Uber das Morphium, eine neue salzfähige grundlage, und die mekonsäure, als hauptbestandtheile des opium. Gilbert Ann Physick. 1817;55:56-89. doi:10.1002/andp.18170550104

7. Bovill J, Dahan A, van Kleef J. Opium-a drug ancient and modern. Adv Anesth Analg. 2007;22:12-27.

8. Marquette University N. Analeptic. Wikipedia. 2020. Available from: https://en.wikipedia.org/wiki/Analeptic. Accessed November 20, 2020.

9. Brand L, Mark LC. Why use analeptics? Bull N Y Acad Med. 1962;38:702-704.

10. Couch G, White M, de Gray L. Central nervous system stimulants: basic pharmacology and relevance to anaesthesia and critical care. Anaesth Intensive Care Med. 2020;21(10):503-511. doi:10.1016/j. mpaic.2020.07.005

11. Stewart GG. A history of the medicinal use of tobacco 1492-1860. Med Hist. 1967;11(3):228-268. doi:10.1017/S0025727300012333

12. Talcott P. Strychnine. In: Peterson M, Talcott P, editors. Small Animal Toxicology. 2nd ed. W.B. Saunders; 2006:1076-1082.

13. Symons AJ, Boyle AK. Accidental strychnine poisoning: a case report. Br J Anaesth. 1963;35(1):54-56. doi:10.1093/bja/35.1.54

14. Hickel E. The laboratory as an adjunct to historical research. Pharm Hist. 1968;10(3):105-108.

15. Dutertre S, Becker CM, Betz H. Inhibitory glycine receptors: an update. J Biol Chem. 2012;287(48):40216-40223. doi:10.1074/jbc. R112.408229
16. Hur MH, Havalad V, Clardy C. Strychnine: old remedy, silent killer. Pediatr Ann. 2019;48(5):e205-e207. doi:10.3928/19382359-20190422-04

17. Gupta R. Non-anticoagulant rodenticides. In: Gupta R, editor. Veterinary Toxicology. 2nd ed. New York, New York: Academic Press; 2012:698-711.

18. Gurd FB, Vineberg AM, Bourne W. Further experiences in the use of spinal anesthesia for thoracoplasty. Ann Surg. 1939;110(5):872-877. doi:10.1097/00000658-193911000-00007

19. Schmidt C, Chen K. Ephedrin and Related Substances. Williams \& Wilkins Company: Baltimore, MD; 1930.

20. A B, J A, M T, P P. Strychnine. Accessed April 22, 2019. http://www. inchem. org/documents/pims/chemical/pim507. 1989. Available from: htm\#PartTitle:14.\%20AUTHORS,\%20DATE. Accessed December 12, 2020.

21. AK S, CV M, A K. StatPearls publishing. StatPearls [Internet] Website. 2020. Available from: https://www.ncbi.nlm.nih.gov/books/ NBK547661/. Accessed December 12, 2020.

22. Schmidt C. The action of adrenalin on the respiratory centre, with remarks upon the treatment of severe respiratory depression. J Pharmacol Exp Ther. 1929;35:297.

23. Henderson Y. Respiratory stimulants and their uses. JAMA. 1937;108 (6):471-475. doi:10.1001/jama.1937.92780060004010

24. McLendon K, Preuss CV. Atropine. In: StatPearls. StatPearls Publishing; 2019. Available from: https://www.ncbi.nlm.nih.gov/ books/NBK470551/. Accessed Mar 9, 2021.

25. Steinberg SS, Bellville JW, Seed JC. The effect of atropine and morphine on respiration. J Pharmacol Exp Ther. 1957;121(1):71-77.

26. Tseng W, Sutter ME, Albertson TE. Stimulants and the lung: review of literature. Clin Rev Allergy Immunol. 2014;46(1):82-100. doi:10.1007/s12016-013-8376-9

27. Karch SB. The history of cocaine toxicity. Hum Pathol. 1989;20 (11):1037-1039. doi:10.1016/0046-8177(89)90220-7

28. Gill H, Kelly E, Henderson G. How the complex pharmacology of the fentanyls contributes to their lethality. Addiction. 2019;114 (9):1524-1525. doi:10.1111/add.14614

29. Bause G. Fish poison to merck picrotoxin. Anesthesiologist. 2013;118 (6):1263. doi:10.1097/ALN.0b013e31829a0b4b

30. Cuthbertson DP, Knox JA. The effects of analeptics on the fatigued subject. J Physiol. 1947;106(1):42-58. doi:10.1113/jphysiol.1947. sp004191

31. Ball CM, Featherstone PJ. Coramine and other analeptics. Anaesth Intensive Care. 2018;46(1):3-5. doi:10.1177/0310057X1804600101

32. Scholfield CN. Leptazol antagonises the post-synaptic actions of gamma-aminobutyric acid [proceedings]. Br J Pharmacol. 1979;67 (3):443P-444P.

33. Anonymous.Artificial respiration. Br Med J. 1944;1(4355):848-849. doi:10.1136/bmj.1.4355.848

34. Shulman A, Shaw FH, Cass NM, Whyte HM. A new treatment of barbiturate intoxication. $\mathrm{Br}$ Med J. 1955;1(4924):1238-1244. doi:10.1136/bmj.1.4924.1238

35. Muiesan G, Sorbini CA, Grassi V, et al. A controlled study of three respiratory stimulants in chronic respiratory failure. Dis Chest. 1969;55(1):18-24. doi:10.1378/chest.55.1.18

36. Sanchez-Salazar AA, Pembleton WE, Banerjee CM. Doxapram hydrochloride as a respiratory stimulant in anesthetized man. Anesthesiology. 1963;24:808-812. doi:10.1097/00000542-196311000-00010

37. Adriani J. Respiratory stimulants. Conn Med. 1962;26:320-323.

38. Gaudy JH, Dauthier C, Fourgeaux B. Effect of a new analeptic drug, almitrine, on fentanyl-induced respiratory depression and analgesia in man. $\mathrm{Br} J$ Anaesth. 1982;54(6):617-621. doi:10. 1093/bja/54.6.617

39. B'chir A, Mebazaa A, Losser MR, Romieu M, Payen D. Intravenous almitrine bismesylate reversibly induces lactic acidosis and hepatic dysfunction in patients with acute lung injury. Anesthesiology. 1998;89(4):823-830. doi:10.1097/00000542-19981 0000-00005 
40. Golder FJ, Hewitt MM, McLeod JF. Respiratory stimulant drugs in the post-operative setting. Respir Physiol Neurobiol. 2013;189 (2):395-402. doi:10.1016/j.resp.2013.06.010

41. Nehlig A, Daval JL, Debry G. Caffeine and the central nervous system: mechanisms of action, biochemical, metabolic and psychostimulant effects. Brain Res Brain Res Rev. 1992;17(2):139-170.

42. Evans TW, Tweney J, Waterhouse JC, Nichol J, Suggett AJ, Howard P. Almitrine bismesylate and oxygen therapy in hypoxic cor pulmonale. Thorax. 1990;45(1):16-21. doi:10.1136/thx.45.1.16

43. Schmickl CN, Owens RL, Orr JE, Edwards BA, Malhotra A. Side effects of acetazolamide: a systematic review and meta-analysis assessing overall risk and dose dependence. BMJ Open Respir Res. 2020;7:1. doi:10.1136/bmjresp-2020-000557

44. Discussion B List of CNS stimulants: pharmacology. 2020. Available from: https://www.biologydiscussion.com/pharmacology-2/list-of-cns -stimulants-pharmacology/74154. Accessed December 12, 2020.

45. Edwards G, Leszczynski S. A double-blind trial of five respiratory stimulants in patients in acute ventilatory failure. Lancet. 1967;290 (7509):226-229. doi:10.1016/S0140-6736(67)92296-9

46. Henderson-Smart D, Steer P. Doxapram treatment for apnea in preterm infants. Cochrane Database Syst Rev. 2004;4:CD000074.

47. Imam MZ, Kuo A, Smith MT. Countering opioid-induced respiratory depression by non-opioids that are respiratory stimulants. F1000Res. 2020;9. doi:10.12688/f1000research.21738.1

48. Wiese BM, Liktor-Busa E, Levine A, et al. Cannabinoid-2 agonism with am2301 mitigates morphine-induced respiratory depression. Cannabis Cannabinoid Res. 2020. doi:10.1089/can.2020.0076.

49. Greer JJ, Smith JC, Feldman JL. Role of excitatory amino acids in the generation and transmission of respiratory drive in neonatal rat. J Physiol. 1991;437:727-749. doi:10.1113/jphysiol.1991.sp018622

50. Funk GD, Smith JC, Feldman JL. Generation and transmission of respiratory oscillations in medullary slices: role of excitatory amino acids. J Neurophysiol. 1993;70(4):1497-1515. doi:10.1152/jn.1993.70.4.1497

51. Pace RW, Mackay DD, Feldman JL, Del Negro CA. Inspiratory bursts in the preBotzinger complex depend on a calcium-activated non-specific cation current linked to glutamate receptors in neonatal mice. J Physiol. 2007;582(Pt 1):113-125. doi:10.1113/jphysiol.2007.133660
52. Mueller R, Li YX, Hampson A, et al. Benzoxazinones as potent positive allosteric AMPA receptor modulators: part I. Bioorg Med Chem Lett. 2011;21(13):3923-3926. doi:10.1016/j.bmcl.2011.05.026

53. Mueller R, Rachwal S, Tedder ME, et al. Substituted benzoxazinones as potent positive allosteric AMPA receptor modulators: part II. Bioorg Med Chem Lett. 2011;21(13):3927-3930. doi:10.1016/j.bmcl. 2011.05.024

54. Jonkman K, van Rijnsoever E, Olofsen E, et al. Esketamine counters opioid-induced respiratory depression. $\mathrm{Br} J$ Anaesth. 2018;120 (5):1117-1127. doi:10.1016/j.bja.2018.02.021

55. McCartney CE, McClafferty H, Huibant JM, Rowan EG, Shipston MJ, Rowe IC. A cysteine-rich motif confers hypoxia sensitivity to mammalian large conductance voltage- and Ca-activated K (BK) channel alpha-subunits. Proc Natl Acad Sci U S A. 2005;102(49):17870-17876. doi:10.1073/pnas.0505270102

56. McLeod JF, Leempoels JM, Peng SX, Dax SL, Myers LJ, Golder FJ. GAL-021, a new intravenous BKCa-channel blocker, is well tolerated and stimulates ventilation in healthy volunteers. $\mathrm{Br} J$ Anaesth. 2014;113(5):875-883. doi:10.1093/bja/aeu182

57. Dahan A, van der Schrier R, Smith T, Aarts L, van Velzen M, Niesters M. Averting opioid-induced respiratory depression without affecting analgesia. Anesthesiology. 2018;128(5):1027-1037. doi:10. 1097/ALN.0000000000002184

58. van der Schier R, Roozekrans M, van Velzen M, Dahan A, Niesters M. Opioid-induced respiratory depression: reversal by non-opioid drugs. F1000Prime Rep. 2014;6::79. doi:10.12703/P6-79

59. Spivey WH. Flumazenil and seizures: analysis of 43 cases. Clin Ther. 1992;14(2):292-305.

60. Haverkos GP, DiSalvo RP, Imhoff TE. Fatal seizures after flumazenil administration in a patient with mixed overdose. Ann Pharmacother. 1994;28(12):1347-1349. doi:10.1177/106002809402801204
Journal of Pain Research

\section{Publish your work in this journal}

The Journal of Pain Research is an international, peer reviewed, open access, online journal that welcomes laboratory and clinical findings in the fields of pain research and the prevention and management of pain. Original research, reviews, symposium reports, hypothesis formation and commentaries are all considered for publication. The manuscript

Submit your manuscript here: https://www.dovepress.com/journal-of-pain-research-journa management system is completely online and includes a very quick and fair peer-review system, which is all easy to use. Visit http:// www.dovepress.com/testimonials.php to read real quotes from published authors. 